\title{
Tooth-implant Connection: A Literature Review
}

\author{
Safoura Ghodsi, Sasan Rasaeipour
}

\section{ABSTRACT}

Aim: The aim of this review is to summarize and discuss the available information concerning the connection between the tooth and implant in a fixed partial denture.

Background: Although implant-supported prosthesis (ISP) has substantial biological and biomechanical advantages, due to the extensive use of implant in partially edentulous patients, encounter to cases of obligatory connection between the tooth and implant is not rare. However, because of their differences, especially in support mechanism, long-term prognosis of this treatment method is a special debate in dental literature.

Materials and methods: The literature published over the past 25 years was searched through PubMed, Medline, Google and indexed journals (search terms: tooth implant connection, tooth implant-supported fixed partial denture, tooth implant splinting, implant and tooth). The most valuable and relevant articles were selected and analyzed.

Results and discussion: The existing studies reveal that there are certain conditions in which this method is applicable. The main advantage of the method based on literature reviewed is reducing the need to the removable prosthesis in patients that otherwise require it. The disadvantages of this connection, mainly due to different movement range of components under loading, reportedly will be minimized if some guidelines are followed.

Clinical significance: According to available studies, this literature review supports tooth-implant connection technique where indicated, with complete attention to prudent guidelines. Further researches preferably concentrating on new methods and also long-term longitudinal studies are certainly needed before this approach can be widely used.

Keywords: Dental prosthesis, Implant supported, Connection, Edentulous, Partially/Rehabilitations, Tooth intrusion, Literature review.

How to cite this article: Ghodsi S, Rasaeipour S. Tooth-implant Connection: A Literature Review. World J Dent 2012;3(2):213-219.

\section{Source of support: Nil}

Conflict of interest: None declared

\section{INTRODUCTION}

'All truth is definable only at the time and instance of its application'. ${ }^{1}$

Every historical truth should be evaluated precisely with development in information and technology. This statement also applies to tooth-implant connection. It appears that connecting tooth to implant despite this historical truth that 'they cannot be directly connected' is a useful option in appropriate cases. ${ }^{1}$

Based on declaration by 'Academy of osseointegration' in 2001, one of the most argued issues in the field of fixed partial dentures (FPDs) support is probably the combination of teeth and implants. ${ }^{2}$

The history of connecting implant to the tooth dates back to early $1980 \mathrm{~s}$, when there was no implant with antirotational feature, and connecting the implant to the natural tooth or another implant was an obligation to prevent rotation of the restoration and its related complications, such as screw loosening or fracture. Although Branemark implant (Noble Biocare, Yorba Linda, Calif), introduced in 1982, had hex head for aligning the implant during insertion, because of flat (non-hex) abutment surface, such connection was still a necessity. In 1984, core-vent (Zimmer Dental, Carlsbad, Calif) introduced the first antirotation implant abutment that had an 'adjustable narrow neck' and this was the weak link of the system. In 1986, the first screw-retained abutment was introduced. Because of lack of antirotational feature in these abutments, the screw represented the weakest link and was prone to failure. After all in 1988 Dr John Beumer of the UCLA university introduced the first screw- retained abutment with anti-rotational feature: 'The UCLA abutment'. With this invention, creation of freestanding implant restoration without the obligation to connecting it to other implants and teeth became feasible for the first time. ${ }^{1}$

Today connecting the implant to the tooth is not always a necessity but there are conditions where such a connection is our first choice or even an exigency. However, because of inherent differences between these two components (tooth and implant) particularly in their supporting mechanisms and survival rate, as well as a higher risk of technical complications in tooth-implant supported fixed prosthesis, this procedure has been a topic of argumentation and controversies in last decades. Some studies reported no problem in connecting implant to natural teeth, and drew the conclusion that it is indeed beneficial to use such connection in fixed prosthesis, ${ }^{3-6}$ whereas there are implant dentists worldwide who avoid splinting tooth and implant concerning of potential problems. ${ }^{7}$

To have a sound judgment regarding such treatment modality, it is beneficial to review the available studies concerning tooth-implant connection.

\section{MATERIALS AND METHODS}

The literature published over the past 25 years was searched (search terms: Tooth implant connection, tooth implant supported fixed partial denture, tooth implant splinting, 
implant and tooth) through PubMed, Medline, Google and indexed journals. The most valuable and relevant articles (consisting a total of 76 articles) were selected and analyzed. This study will review available published articles concerning tooth-implant connection in the following categories:

1. The rationale for such a connection.

2. The origin and cause of potential problems.

3. The advantages and disadvantages of this method.

4. The potential risks

5. The available method of connecting tooth to implant

6. Expected long-term complications and useful guidelines to reduce them.

A summary of this review follows:

\section{REVIEW RESULTS AND DISCUSSION}

1. The rational of using tooth-implant connection ${ }^{1,8-10}$

The reasons of connecting the tooth to the implant are summarized in five categories:

- To gain support from the tooth or implant: As an example in the patients with bruxism, properioception of the tooth may help to reduce applied stresses to the implants. ${ }^{1,8,9}$

- Theabsence of otheroptions: Because of systemic, local or financial limitations, bone augmentation and insertion of additional implants are not always possible. Cantilever on one implant, implants narrower than $4 \mathrm{~mm}$ (type B), or in situations of moderate-to-severe force factors are not recommended. ${ }^{10}$

- To preserve a key tooth or teeth with good prognosis. ${ }^{1,8}$

- To provide stability against rotational forces. ${ }^{1,9}$

- For esthetic reasons: ${ }^{1,8}$ Implants unlike natural teeth always present challenges with regard to esthetic. Furthermore, retaining the tooth preserves the adjacent papillae.

2. The causes of potential problems: ${ }^{11-25}$

The virtual problems refer mainly to the difference in the tooth and implant supporting mechanisms. ${ }^{11-15} \mathrm{PDL}$ causes greater movement in the tooth. Lateral movement of the teeth is about 56 to $108 \mu \mathrm{m}$ in comparison to 10 to $50 \mu \mathrm{m}$ in the implant with the same force magnitude; apical movement of the tooth is 25 to $100 \mu \mathrm{m}$ and that of the implant is 3 to $5 \mu \mathrm{m} .{ }^{11}$ When force is applied to the pontic connecting the tooth to the implant, this difference can cause greater stress on the implant.

The other cause of potential problems is difference in survival rates of the tooth and implant. The tooth, as opposed to the implant, might decay or need endodontic therapy. These problems may cause the whole system failure. In the studies on survival rate of the toothsupported FPDs vs the implant (ITI system), the difference was noticeable ${ }^{14}$ whereas tooth-implant supported FPDs (TISP) in comparison to the implant supported FPDs (ISP) do not significantly show more failure rate. ${ }^{16-18}$

In other studies, implant survival and prosthesis success rate in TISP have been evaluated, the values being between 80 and $100 \%{ }^{19-25}$

3. The advantages and disadvantages of connecting the tooth to the implant

\section{A. Advantages: ${ }^{26,27}$}

In the literature, the benefits of tooth-implant connection have been listed as follows:

- Broadened treatment possibilities ${ }^{26,27}$

- Reduced cost (reduction of implant numbers) ${ }^{27}$

- Protective value of properiception provided by tooth $^{26,27}$

- Desire to splint a mobile key tooth to an implant ${ }^{27}$

- Additional support for total load on dentition 1,8,9,26,27

- Reduction of the need for a cantilever ${ }^{26,27}$

- Preservation of the papilla adjacent the tooth for esthetic and phonetic reasons

- More favorable bone reaction when the bridge is connected to both the implant and teeth. ${ }^{26}$ Cavicchia reported that problems such as loosening and fracture of fixation screws and abutments, ceramic fracture and tooth migration seem to occur more frequently in free standing implants compared to the tooth connected restorations. ${ }^{5}$ This result can be related to the decrease bite force in tooth-implant supported prosthesis because of tooth related properioception.

B. Disadvantages: ${ }^{8,27-48}$

Potential disadvantages consist of:

- Technical problems, such as implant or tooth fracture, tooth intrusion, cement bond breakdown, screw loosening and prosthetic materials fracture.

- Biological problems, such as peri-implantitis, endodontic problems, lose of tooth or implant, caries and tooth fracture. $8,27-32$

Intrusion of the tooth is one of the most debated topics in the literature. ${ }^{8,22,24,30,33-47}$ Intrusion of the tooth in TISP has been reported particularly with nonrigid connectors or coping and telescopes with provisional cement or with no cement. The interesting point is that in one study the number of intruded teeth was significantly more in patients with intact periodontal support. ${ }^{22}$ 
Rieder and Parel found that $50 \%$ of the intrusions occurred in the individuals with parafunctional habits, especially bruxism. ${ }^{48}$

The discussed causes of the intrusion consist of: $8,9,30,39,42,46,47$

- Differential energy dissipation ${ }^{9}$

- Friction between the matrix and patrix wall in nonrigid connectors. $8,30,47$

- Debris impaction in nonrigid connectors $8,30,47$

- Impaired rebound memory of the tooth ${ }^{8,39}$

- FDPs flexure ${ }^{42,47}$

- Disuse atrophy of PDL 39

- Mandibular flexure (average value: $0.9 \mathrm{~mm})^{46,47}$

- Transfers of microshock waves to the natural tooth $^{40,42}$

Srinivasan has a contradictory opinion about this reported event. Based on orthodontic references, he believes that 'the forces should be light, continues and controlled to bring about intrusion without damaging the tooth, in tooth-implant connection it is not the case'. ${ }^{33}$

4. The potential risks of connecting the tooth to the implant are as follows: $:^{1,5,8,28-31}$

In the literature, the virtual pitfalls of such connection have been listed as follows:

A. Overloading:

Connecting an implant to the tooth depends on occlusal force factors, tooth mobility and the number of other implants already in the mouth can overload the implant and its peripheral bone.

Based on the literature, load duration appears to have a greater influence than load intensity on stress distribution in the bone. The stress of transitional loads, because of viscoelastic properties of the PDL, is better distributed whereas static load causes progressive deformation of the PDL and, therefore, the tooth would sink into the alveolus; then the bridge would act as a cantilever on the implant and overstress it. $5,8,29$

B. Loss of irretrievability (when the screw is loosened or broken).

C. Progressive bone loss as follows:

In a study with the follow-up ranging from 1.5 to 15 years, the authors found a statistically significant difference in marginal bone loss between the free standing implant prosthesis and TISP, 8,31 yet there are controversies about this result. In one study, slight apposition of the marginal bone was noted around the implant in TISP. ${ }^{32}$ The stability of the marginal bone over time in this study was in accordance with similar findings in other studies. ${ }^{16,24}$
5. The available methods of connection are as follows: Celso Hita-Carrillo has classified the methods of connection into two main groups: Rigid and nonrigid connection. Nonrigid connections could be in the form of attachment or intermobile element (IME). ${ }^{49}$

- Rigid connection $3,6,20,22,25,32,39,49-60$

Authors have different opinions about rigid connection. The presented opinions are as follows:

- Some authors believe that rigid connection of the teeth to the implants is not rational due to the adverse effects on the implant in long-term. ${ }^{9}$

- It will produce greater marginal bone loss, with a corresponding increase in probing depth around the supporting abutment (tooth or implant). ${ }^{49}$

- Clinicians, who advocate connecting the tooth to the implant rigidly, accept the differential mobility of the implant and natural teeth, but they deem there is sufficient flexibility in the implant complex to compensate this and allow sharing of the lead. $3,46,51$

- Long-term studies suggest that the tooth and boneimplant components were able to undergo some deformation to compensate for the differences in the implant and tooth resiliency under functional load. ${ }^{6,52-58}$

- Rigid connection achieves better outcomes with regard to avoiding dental intrusion. ${ }^{22,25,39}$

- Finite element analysis showed greater stress concentrated on the neck of the implant and the connector near the tooth. ${ }^{50,59}$

- Lin CL in 2006 reported micorgap formation between the implant abutment and the fixture under the lateral occlusal forces. ${ }^{60}$

The types of such a connection consist of: Rigid screw retained abutments, coping with permanent cement and soldered connectors. ${ }^{27,56}$

Several different solutions have been proposed to compensate for different resiliencies of the tooth and implant: Internal flexion elements in the implant- abutment connection, telescopic coping that are cemented or freefloating and internal nonrigid keyway attachments (stressbreakers). ${ }^{28}$

- Nonrigid connection

A. Intermobile elements (IME)

There are few studies about these elements. It has been said that these elements provide flexibility to compensate for the mobility of the tooth. ${ }^{61-64}$ Uysal in 1996 reported that these elements reduced the strain up to $60 \%$ compared to the rigid internal elements. ${ }^{62}$ In an in vitro study, it was demonstrated 
that IME did not contribute to the flexibility of the system and the bending force was transmitted to the retaining screw of the implant abutment. ${ }^{9}$

B. Attachments

It has been mentioned that the attachments reduced the level of stresses in the bone, ${ }^{65}$ because it breaks the stress transfer process and more efficiently compensates for dissimilar mobility of the tooth and implant ${ }^{50,66}$ but intrusion in 3 to $4 \%$ of the cases has reported to cause cantilever formation on the implant and increase the unfavorable stress values in the implant and prosthesis. . $^{38,48,67,68}$

Finite element analysis showed stress concentration around the non-rigid connector. ${ }^{67}$

Von Oosterwyck, Naert and Nishimura mentioned that rigid connection compared to free-standing implants or nonrigid connections overstress the implants and result in greater bone loss around the implant; ${ }^{8,56,69}$ however, along with most of other authors, they expressed their preference for rigid connection over nonrigid connectors. $8,56,67,69,70$

Hoffmann reported that nonrigid connections drastically reduce the stress on the superstructure while increasing the forces on the supporting teeth and implants. ${ }^{71}$

6. Long-term complications and useful guidelines

- Pjetursson reported the fracture of the veneer material as the most common complication that is more frequent in ISP (11.9\%) than TISP (7.2\%). He also mentioned that loss of retention was more frequent in TISP (7.3\%) than ISP (5.7\%). ${ }^{72}$

- Bragger demonstrated that technical and biological complications after 10 years were more prevalent in TISP (50\%) than ISP (45.5\%). ${ }^{17}$

- Gunne reported the marginal bone loss after 10 years of $0.5 \mathrm{~mm}$ in TISP and 0.6 to $0.7 \mathrm{~mm}$ in ISP. ${ }^{16}$

- Several studies reported higher complications in TISP in comparison to ISP and attributed them to the risks of tooth complications, like carious lesions, loss of vitality and periodontal problems that added to the complications correlated to the implant. ${ }^{17,20,73-75}$

In order to reduce the complications and improve TISP performance, some studies proposed useful guidelines to follow: $:^{3,5,8-10,27,28,76}$

- The natural tooth should have superior stability through long rooted, multirooted, negligible mobility, adequate periodontal support or splinting to an extra tooth or teeth. $5,10,27,28$

- The implant should have substantial size and be in type I or II quality bone. ${ }^{10}$

- Nonrigid attachments should be avoided as they increase the incidence of tooth intrusion. In case of inevitable use of these connectors, connect the attachment to the implant restoration (between the pontic and the implant). ${ }^{3,8,9,10,27}$

- The pontic should be of short span. ${ }^{10,27}$

- The implant component and retaining screw must exhibit some degree of flexibility. ${ }^{3}$

- Take care to eliminate or minimize lateral forces and unbalanced tooth contacts in centric and excursive movements. ${ }^{10,11,76}$

- Consider bruxism to be a risk factor and manage it with an antibruxism splint. ${ }^{76}$

- Use highly retentive cement with superior retentive preparation design on the tooth abutment. ${ }^{10}$

- If telescopic crown or coping are utilized, avoid using temporary cements, particularly avoid the nocement coping technique. ${ }^{3,8,10,11,27}$

- Because of the potential tooth intrusion, consider frequent occlusal adjustment as an important followup step. ${ }^{76}$

\section{CONCLUSION}

Although the best option in partially edentulous patients appears to be complete implant-supported prosthesis, there are specific conditions in which the dentist should select between connecting the implant to the tooth in a fixed partial denture or using a removable denture, extraction of remaining teeth, or accept the related risks of other treatment options. Based on literature reviewed, using implant-tooth splinting can be reliable treatment option in properly selected patients; there is no scientific support for extraction of the teeth to avoid connecting them to the implant.

Like every other dental practice, this territory requires proper patient selection and complete attention to all the details for success. This method has its own advantages, disadvantages, risks and complications, but what justifies its application is risks- benefit evaluation with attention to patient requirements.

However, due to limitations of available literature with regard to sample sizes, duration of studies, disparity of study groups and incoherent study situations, it is extremely difficult to compare the available literature and obtain absolute conclusion. These same features make more longitudinal studies necessary before this method can be recommended as the first choice of treatment. Yet, in specific situations, it can be a viable alternative method with an acceptable success rate.

\section{Clinical Significance}

According to available studies, this literature review supports tooth-implant connection technique where indicated, with complete attention to prudent guidelines. 


\section{ACKNOWLEDGMENT}

The authors would like to thank Dr Nasrin Shokrpour at Center for Development of Clinical Research of Nemazee Hospital for editorial assistance.

\section{REFERENCES}

1. Spear F. Connecting teeth to implants: The truth about a debated technique. J Am Dent Assoc 2009;140(5):587-93.

2. Iacono VJ, Cochran DL. State of the science on implant dentistry: A workshop developed using an evidence-based approach. Int J Oral Maxillofac Implants 2007;22(Suppl):7-10.

3. Rangert B, Gunne J, Sullivan DY. Mechanical aspects of a Brånemark implant connected to a natural tooth: An in vitro study. Int J Oral Maxillofac Implants 1991;6(2):177-86.

4. Rangert B. Biomechanics of the Brånemark system. Aust Prosthodont J 1995;9(Suppl):39-48.

5. Cavicchia F, Bravi F. Free-standing vs tooth-connected implant supported partial fixed restorations: A comparative retrospective clinical study of the prosthetic results, International Journal of Oral and Maxillofacial Implants 1994;9:711-18.

6. Van Steenberghe D. A retrospective multicenter evaluation of the survival rate of osseointegrated fixtures supporting fixed partial prostheses in the treatment of partial edentulism. J Prosthet Dent 1989 Feb;61(2):217-23.

7. McGlumphy EA, Campagni WV, Peterson LJ. A comparison of the stress transfer characteristics of a dental implant with a rigid or a resilient internal element. J Prosthet Dent 1989;62: 586-93.

8. Naert IE, Duyck JA, Hosny MM, Van Steenberghe D. Freestanding and tooth-implant connected prostheses in the treatment of partially edentulous patients. Part I: An up to 15-year clinical evaluation. Clin Oral Implants Res 2001;12(3):237-44.

9. Chee W, Jivraj S. Connecting implants to teeth. Br Dent J 2006;201(10):629-32.

10. Misch CE. Contemporary implant dentistry (3rd ed). Mosby Elsevier; 2008;Ch. 12.:258-64.

11. Kim Y, Oh TJ, Misch CE, Wang HL. Occlusal considerations in implant therapy: Clinical guidelines with biomechanical rationale. Clin Oral Implants Res 2005;16(1):26-35.

12. Bennani V, Schwass D, Chandler N. Gingival retraction techniques for implants versus teeth: Current status. J Am Dent Assoc 2008;139(10):1354-63.

13. Yu-Ying Chen, Chung-Ling Kuan, Yi-Bing Wang. Implant occlusion: Biomechanical considerations for implant-supported prostheses. J Dent Sci 2008;3(2):65-74.

14. Thomas MV, Beagle JR. Evidence-based decision-making: Implants versus natural teeth. Dent Clin North Am 2006;50(3):451-61.

15. Palmer R. Teeth and implants. Br Dent J 1999;187(4):183-88.

16. Gunne J, Astrand P, Lindh T, Borg K, Olsson M. Tooth-implant and implant-supported fixed partial dentures: A 10-year report. Int J Prosthodont 1999;12(3):216-21.

17. Brägger U, Karoussis I, Persson R, Pjetursson B, Salvi G, Lang $\mathrm{N}$. Technical and biological complications/failures with single crowns and fixed partial dentures on implants: A 10-year prospective cohort study. Clin Oral Implants Res 2005; 16(3):326-34.
18. Steflik DE, Koth DL, Robinson FG, McKinney RV, Davis BC, Morris CF, Davis QB. Prospective investigation of the singlecrystal sapphire endosteal dental implant in humans: Ten-year results. J Oral Implantol 1995;21(1):8-18.

19. Lindh T. Should we extract teeth to avoid tooth-implant combinations? J Oral Rehabil 2008;35 Suppl 1:44-54.

20. Lang NP, Pjetursson BE, Tan K, Brägger U, Egger M, Zwahlen M. A systematic review of the survival and complication rates of fixed partial dentures (FPDs) after an observation period of at least 5 years. II. Combined tooth-implant-supported FPDs. Clin Oral Implants Res 2004;15(6):643-53.

21. Palmer RM, Howe LC, Palmer PJ. A prospective 3-year study of fixed bridges linking Astra Tech ST implants to natural teeth. Clin Oral Implants Res 2005;16(3):302-07.

22. Cordaro L, Ercoli C, Rossini C, Torsello F, Feng C. Retrospective evaluation of complete-arch fixed partial dentures connecting teeth and implant abutments in patients with normal and reduced periodontal support. J Prosthet Dent 2005;94(4):313-20.

23. Brägger U, Aeschlimann S, Bürgin W, Hämmerle $\mathrm{CH}$, Lang NP. Biological and technical complications and failures with fixed partial dentures (FPD) on implants and teeth after four to five years of function. Clin Oral Implants Res 2001;12(1): 26-34.

24. Lindh T, Dahlgren S, Gunnarsson K, Josefsson T, Nilson H, Wilhelmsson P, Gunne J. Tooth-implant supported fixed prostheses: A retrospective multicenter study. Int J Prosthodont 2001;14(4):321-28.

25. Nickenig HJ, Schäfer C, Spiekermann H. Survival and complication rates of combined tooth-implant-supported fixed partial dentures. Clin Oral Implants Res 2006;17(5):506-11.

26. Gunne J, Astrand P, Ahlén K, Borg K, Olsson M. Implants in partially edentulous patients. A longitudinal study of bridges supported by both implants and natural teeth. Clin Oral Implants Res 1992;3(2):49-56.

27. Greenstein G, Cavallaro J, Smith R, Tarnow D. Connecting teeth to implants: A critical review of the literature and presentation of practical guidelines. Compend Contin Educ Dent 2009;30(7):440-53.

28. Nimchuck D. Can dental root form implants be successfully bridged to natural teeth? Canadian Journal of Restorative Dentistry and Prosthodontics 2008 Aug;1-2:35-37.

29. Menicucci G, Mossolov A, Mozzati M, Lorenzetti M, Preti G. Tooth-implant connection: Some biomechanical aspects based on finite element analyses. Clin Oral Implants Res 2002;13(3):334-41.

30. Akpinar I, Anil N, Parnas L. A natural tooth's stress distribution in occlusion with a dental implant. J Oral Rehabil 2000;27(6):538-45.

31. Naert I, Koutsikakis G, Quirynen M, Duyck J, van Steenberghe D, Jacobs R. Biologic outcome of implant-supported restorations in the treatment of partial edentulism. Part 2: A longitudinal radiographic study. Clin Oral Implants Res 2002;13(4):390-95.

32. Akça K, Uysal S, Cehreli MC. Implant-tooth-supported fixed partial prostheses: Correlations between in vivo occlusal bite forces and marginal bone reactions. Clin Oral Implants Res 2006;17(3):331-36.

33. Srinivasan M, Padmanabhan TV. Intrusion in implant-toothsupported fixed prosthesis: An in vitro photoelastic stress analysis. Indian J Dent Res 2008;19(1):6-11. 
34. Ormianer Z, Brosh T, Laufer BZ, Shifman A. Strains recorded in a combined tooth-implant restoration: An in vivo study. Implant Dent 2005;14(1):58-62.

35. Wang TM, Lee MS, Kok SH, Lin LD. Intrusion and reversal of a free-standing natural tooth bounded by two implant-supported prostheses: A clinical report. J Prosthet Dent 2004;92(5): 418-22.

36. Block MS, Lirette D, Gardiner D, Li L, Finger IM, Hochstedler $\mathrm{J}$, et al. Prospective evaluation of implants connected to teeth. Int J Oral Maxillofac Implants 2002;17(4):473-87.

37. Naert IE, Duyck JA, Hosny MM, Quirynen M, van Steenberghe D. Freestanding and tooth-implant connected prostheses in the treatment of partially edentulous patients Part II: An up to 15-year radiographic evaluation. Clin Oral Implants Res 2001;12(3):245-51.

38. Garcia LT, Oesterle LJ. Natural tooth intrusion phenomenon with implants: A survey. Int J Oral Maxillofac Implants 1998;13(2):227-31.

39. Pesun IJ. Intrusion of teeth in the combination implant-to-naturaltooth fixed partial denture: A review of the theories. J Prosthodont 1997;6(4):268-77.

40. Sheets CG, Earthman JC. Tooth intrusion in implant-assisted prostheses. J Prosthet Dent 1997;77(1):39-45.

41. Abrams L. The phenomenon of natural root intrusion in combined root-form implant cases. Dent Implantol Update 1996;7(5):33-36.

42. Sheets CG, Earthmann JC. Natural tooth intrusion and reversal in implant-assisted prosthesis: Evidence of and a hypothesis for the occurrence. J Prosthet Dent 1993;70(6):513-20.

43. Singer A. Apparent intrusion of natural teeth under an implant supported prosthesis: A clinical report. J Prosthet Dent 1993;70(1):100.

44. English CE. Root intrusion in tooth-implant combination cases. Implant Dent 1993;2(2):79-85.

45. Lill W, Thornton B, Reichsthaler J, Schneider B. Statistical analyses on the success potential of osseointegrated implants: A retrospective single-dimension statistical analysis. J Prosthet Dent 1993;69(2):176-85.

46. Ericsson I, Lekholm U, Brånemark PI, Lindhe J, Glantz PO, Nyman S. A clinical evaluation of fixed-bridge restorations supported by the combination of teeth and osseointegrated titanium implants. J Clin Periodontol 1986;13(4):307-12.

47. Schlumberger TL, Bowley JF, Maze GI. Intrusion phenomenon in combination tooth-implant restorations: A review of the literature. J Prosthet Dent 1998;80(2):199-203.

48. Rieder CE, Parel SM. A survey of natural tooth abutment intrusion with implant-connected fixed partial dentures. Int J Periodontics Restorative Dent 1993;13(4):334-47.

49. Hita-Carrillo C, Hernández-Aliaga M, Calvo-Guirado JL. Toothimplant connection: A bibliographic review. Med Oral Patol Oral Cir Bucal 2010 Mar 1;15(2):387-94.

50. Lin CL, Wang JC, Chang WJ. Biomechanical interactions in tooth-implant-supported fixed partial dentures with variations in the number of splinted teeth and connector type: A finite element analysis. Clin Oral Implants Res 2008;19(1):107-17.

51. Lundgren D, Laurell L. Biomechanical aspects of fixed bridgework supported by natural teeth and endosseous implants. Periodontol 2000;1994 Feb;4:23-40.

52. Weinberg LA, Kruger B. Biomechanical considerations when combining tooth-supported and implant-supported prostheses. Oral Surg Oral Med Oral Pathol 1994;78(1):22-27.
53. Mensor MC, Ahlstrom RH, Scheerer EW. Compliant Keeper system replication of the periodontal ligament protective damping function for implants: Part I. J Prosthet Dent 1998;80(5):565-69.

54. Uysal H, Iplikçioğlu H, Avci M, Gündüz Bilir O, Kural O. An experimental analysis of the stresses on the implant in an implanttooth-supported prosthesis: A technical note. Int J Oral Maxillofac Implants 1997;12(1):118-24.

55. Chapman RJ, Kirsch A. Variations in occlusal forces with a resilient internal implant shock absorber. Int J Oral Maxillofac Implants 1990;5(4):369-74.

56. Nishimura RD, Ochiai KT, Caputo AA, Jeong CM. Photoelastic stress analysis of load transfer to implants and natural teeth comparing rigid and semirigid connectors. J Prosthet Dent 1999; 81(6):696-703.

57. Dixon DL, Fincher M, Breeding LC, Mueninghoff LA. Mechanical properties of a light-polymerizing provisional restorative material with and without reinforcement fibers. J Prosthet Dent 1995;73(6):510-14.

58. Naert I, Quirynen M, van Steenberghe D, Darius P. A six-year prosthodontic study of 509 consecutively inserted implants for the treatment of partial edentulism. J Prosthet Dent 1992;67(2): 236-45.

59. Lin CL, Chang SH, Wang JC. Finite element analysis of biomechanical interactions of a tooth-implant splinting system for various bone qualities. Chang Gung Med J 2006;29(2): 143-53.

60. Lin CL, Wang JC, Kuo YC. Numerical simulation on the biomechanical interactions of tooth/implant-supported system under various occlusal forces with rigid/non-rigid connections. J Biomech 2006;39(3):453-63.

61. Babbush CA, Kirsch A, Mentag PJ, Hill B. Intramobile cylinder (IMZ) two-stage osteointegrated implant system with the intramobile element (IME): part I. Its ratinale and procedure for use. Int J Oral Maxillofac Implants 1987;2(4):203-16.

62. Kay HB. Free-standing versus implant-tooth-interconnected restorations: Understanding the prosthodontic perspective. Int J Periodontics Restorative Dent 1993;13(1):47-69.

63. Saxen M. The new implant systems: A comparative analysis. Dent Manage 1987;27(6):38-42.

64. Uysal H, Iplikcioğlu H, Avci M, Bilir OG, Kural O. Efficacy of the intramobile connector in implant tooth-supported fixed prostheses: An experimental stress analysis. Int J Prosthodont 1996;9(4):355-61.

65. Ozçelik T, Ersoy AE. An investigation of tooth/implantsupported fixed prosthesis designs with two different stress analysis methods: An in vitro study. J Prosthodont 2007;16(2): $107-16$.

66. Burak Özcelik T, Ersoy E, Yilmaz B. Biomechanical evaluation of tooth- and implant-supported fixed dental prostheses with various nonrigid connector positions: A finite element analysis. J Prosthodont 2011;20(1):16-28.

67. Lin CL, Chang SH, Wang JC, Chang WJ. Mechanical interactions of an implant/tooth-supported system under different periodontal supports and number of splinted teeth with rigid and non-rigid connections. J Dent 2006;34(9):682-91.

68. Al-Ansari BH. Use of non-rigid connection between natural teeth and implants to support fixed partial denture. Two years clinical evaluation. Saudi Dental Journal 1996;8(2):96-99.

69. Van Oosterwyck H, Duyck J, Vander Sloten J, Van der Perre $\mathrm{G}$, De Cooman M, Lievens S, et al. The influence of bone 
mechanical properties and implant fixation upon bone loading around oral implants. Clin Oral Implants Res 1998;9(6): 407-18.

70. Mamalis A, Markopoulou K, Kaloumenos C, Analitis A. Splinting osseointegrated implants and natural teeth in partially edentulous patients: A systematic review of the literature and a case report. J Oral Implantol 2010 Nov 12. [Epub ahead of print]

71. Hoffmann O, Zafiropoulos GG. The Tooth-Implant Connection: A Review. J Oral Implantol 2011 Jul 22.

72. Pjetursson BE, Brägger U, Lang NP, Zwahlen M. Comparison of survival and complication rates of tooth-supported fixed dental prostheses (FDPs) and implant-supported FDPs and single crowns (SCs). Clin Oral Implants Res 2007 Jun;18(Suppl 3): 97-113.

73. Lindh T, Bäck T, Nyström E, Gunne J. Implant versus toothimplant supported prostheses in the posterior maxilla: A 2-year report. Clin Oral Implants Res 2001;12(5):441-49.

74. Hosny M, Duyck J, van Steenberghe D, Naert I. Within-subject comparison between connected and nonconnected tooth-to- implant fixed partial prostheses: Up to 14-year follow-up study. Int J Prosthodont 2000;13(4):340-46.

75. Kindberg H, Gunne J, Kronström M. Tooth- and implantsupported prostheses: A retrospective clinical follow-up up to 8 years. Int J Prosthodont 2001;14(6):575-81.

76. Weinberg LA. Therapeutic biomechanics concepts and clinical procedures to reduce implant loading. Part II: Therapeutic differential loading. J Oral Implantol 2001;27(6):302-10.

\section{ABOUT THE AUTHORS}

\section{Safoura Ghodsi}

Prosthodontist, Department of Prosthodontics, Faculty of Dentistry Shiraz University of Medical Sciences, Shiraz, Iran

\section{Sasan Rasaeipour (Corresponding Author)}

Prosthodontist, Department of Prosthodontics, Faculty of Dentistry Shiraz University of Medical Sciences, Shiraz, Iran, Phone: (0098) (711) 6270324 (office), (0098) (711) 6314850 (home), Fax: (0098) (711) 6270325, e-mail: sasanrasaei@yahoo.com 


\section{SUBSCRIPTION INFORMATION}

\begin{tabular}{llrl}
\multicolumn{2}{l}{ Annual Subscription } & & \\
Individual: & $₹$ & 3500.00 & (National) \\
& $\$$ & 200.00 & (International) \\
& & & \\
Institutional: & $₹$ & 5000.00 & (National) \\
& \$ 280.00 & (International)
\end{tabular}

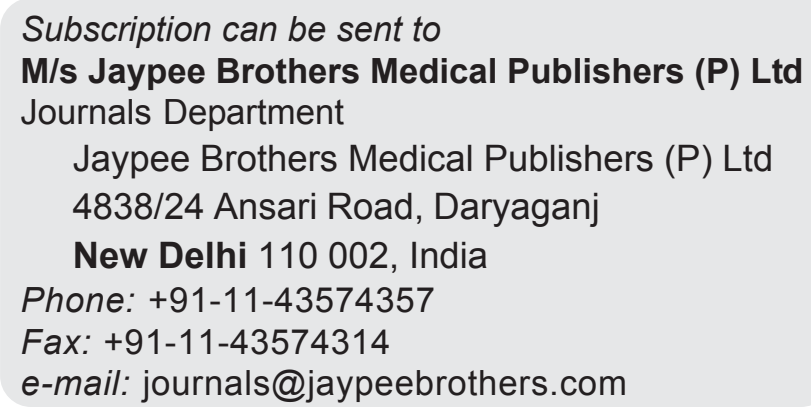

This journal is published quaterly in a year, i.e. March, June, September and December. Dollar rates apply to subscribers in all the countries except India where INR price is applicable. All subscriptions are payable in advance and all the rates include postage. Journals are sent by air to all the countries except Indian subcontinent. Subscriptions are on an annual basis, i.e. from January to December. Payment will be made by dollar, cheque, credit card or directly through our bank account at the following address:
1. Our Banker's Name:
Canara Bank, Netaji Subhash Marg
2. Telephone No:
Darya Ganj, New Delhi 110002
3. Fax No:
$011-23273015,011-23273849$
4. Telex No:
011-23255606
5. Our Current A/c No:
3166291
6. Amount to be Transferred in the Name of:
3828
JAYPEE BROTHERS MEDICAL
PUBLISHERS (P) LTD, NEW DELHI
7. Swift Code No:
CNRB IN BB DFM

For further queries, please do not hesitate to contact at subscriptions@jaypeejournals.com

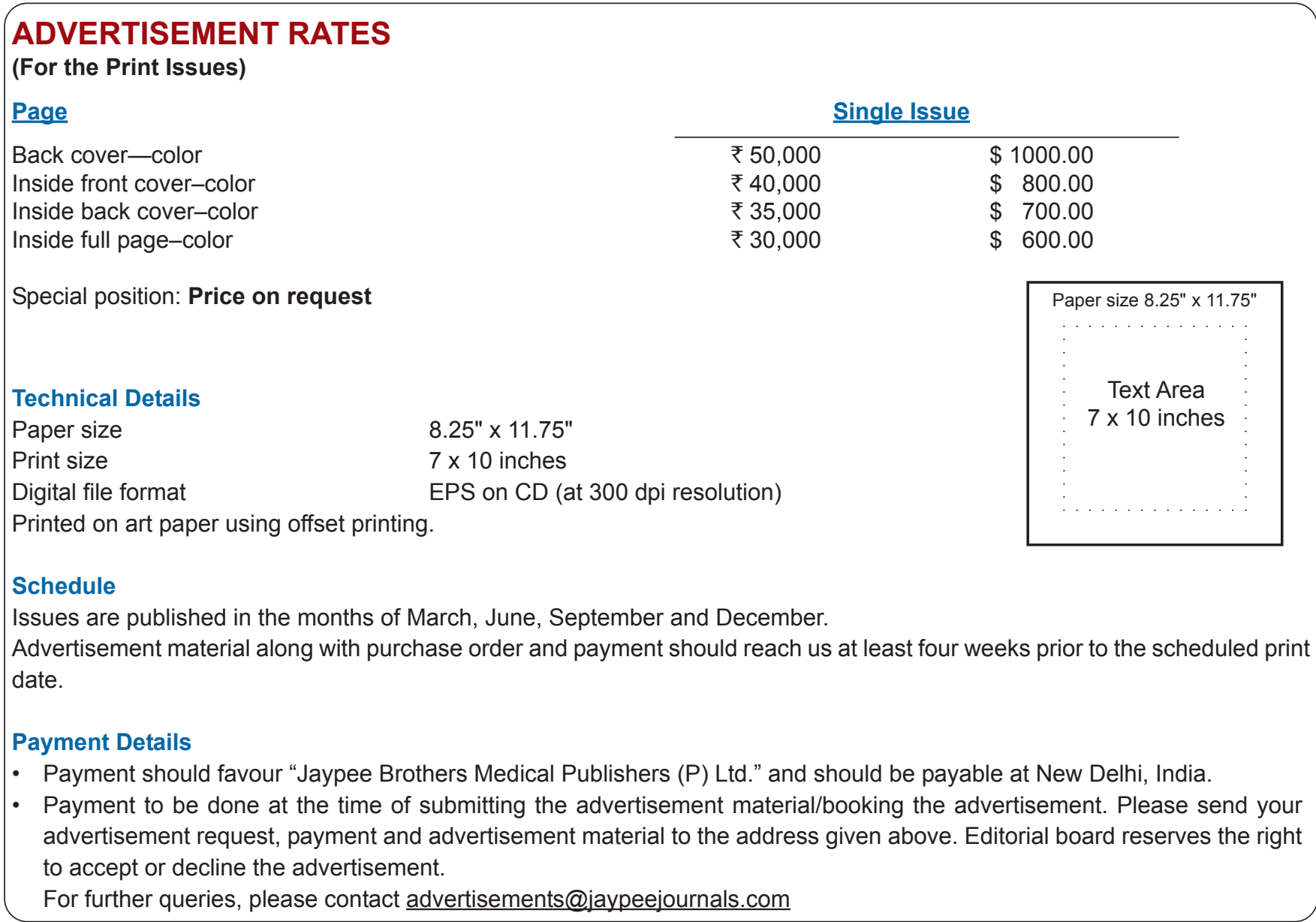

